\title{
El papel de la organización social local en el desarrollo del ecoturismo en México: un estudio comparativo en la Zona Maya de Quintana Roo
}

\section{Cristina Pérez y Sosa* Fernanda Figueroa** Leticia Durand*** Luis Zambrano**** Eduardo García-Frapolli****** Universidad Nacional Autónoma de México (México)}

\begin{abstract}
Resumen: El ecoturismo, como estrategia de desarrollo comunitario, busca alcanzar simultáneamente la conservación y el desarrollo, pero su diseño no considera la complejidad de los contextos locales donde se implementa. Este estudio analiza la relación entre la configuración del contexto sociopolítico local y regional, y el desarrollo de dos iniciativas ecoturísticas en la Zona Maya de Quintana Roo, México, mediante herramientas cualitativas. La implementación de esta estrategia deriva en modelos de ecoturismo diferentes, aun en comunidades de la misma zona. Estas diferencias dependen del tipo de organización social del que provienen las iniciativas, el cual influye en sus dinámicas socioeconómicas y ambientales. Se discute la pertinencia del ecoturismo como estrategia genérica de conservación y desarrollo, los resultados mixtos de su implementación y la importancia de las formas de organización social en su desarrollo.
\end{abstract}

Palabras Clave: Desarrollo; Conservación; Organización social; Ecoturismo; México.

The role of local social organization in the development of ecotourism in Mexico: a comparative study in the Mayan Zone of Quintana Roo

Abstract: Ecotourism, as a community development strategy, seeks to simultaneously achieve conservation and development, but its design does not usually consider the complexity of the local contexts where it is implemented. This study analyzes the role played by the configuration of the local and regional socio-political context in the development of two ecotourism initiatives in the Zona Maya of Quintana Roo, Mexico. Using qualitative tools, the study compares two ecotourism initiatives. Our results show that the implementation of the ecotourism strategies in the region results in different ecotourism models, even in communities of the same zone. These differences depend mainly on the type of social organisation from which the initiatives originate, which influences their socioeconomic and environmental dynamics. The relevance of ecotourism as a generic conservation and development strategy, the mixed results of its implementation and the importance of the forms of social organisation in its development are discussed.

Keywords: Development; Conservation; Social organization; Ecotourism; Mexico.

\section{Introducción}

Desde hace varias décadas, el ecoturismo ${ }^{1}$ se ha planteado como una actividad idónea para incrementar los ingresos de las comunidades que viven en áreas naturales protegidas (ANP) y, promover así, la conservación de los recursos naturales (OMT, 2011). De hecho, en el discurso más convencional, el ecoturismo se concibe como una "actividad sustentable", pues se asume que no genera impactos ambientales importantes (Jamal et al., 2006). En México, desde la década de 1990 el ecoturismo

\footnotetext{
* Universidad Nacional Autónoma de México (México); E-mail: mcpys@comunidad.unam.mx

** Universidad Nacional Autónoma de México (México); E-mail: ffigueroa@ciencias.unam.mx; https://orcid.org/0000-0001-6950-0490

*** Universidad Nacional Autónoma de México (México); E-mail: eticiad@unam.mx

**** Universidad Nacional Autónoma de México (México); E-mail: zambrano@ib.unam.mx; https://orcid.org/0000-0002-8632-0712

****** Universidad Nacional Autónoma de México (México); E-mail: garcia.frapolli@gmail.com
} 
se promueve como una herramienta de conservación y desarrollo, en parte debido a la integración del concepto de desarrollo sustentable a la agenda ambiental en 1992, que constituye la base de los principales acuerdos ambientales internacionales (Aguado et al., 2009) y, más recientemente por la influencia del neoliberalismo en las políticas públicas de conservación (la llamada conservación neoliberal), que favoreció estrategias de mercado en la búsqueda de conservación y el desarrollo (Igoe et al., 2010; Büscher et al., 2012). El ecoturismo también cobra relevancia debido al reconocimiento, a nivel global, del impacto ambiental del turismo de masas en las comunidades y su entorno, lo que impulsó el desarrollo de un modelo de turismo de menor impacto ambiental. Así, el ecoturismo se incorporó como un nuevo segmento de turismo dirigido a espacios naturales, poco poblados y desarrollados (Croall, 1995; Barkin y Pailles, 1999). El ecoturismo busca también generar conciencia ambiental y cultural, tanto en los turistas como en los pobladores, particularmente en las ANP, por lo que el aumento de ANP en México, desde la década de 1990, facilitó la creación de numerosas iniciativas ecoturísticas (Barkin, 2005; Guerrero-Rodríguez, 2010).

En México, el ecoturismo ha sido promovido por agencias internacionales, como el Banco Mundial, el Banco Interamericano de Desarrollo y el Fondo Monetario Internacional, bajo la perspectiva del desarrollo sostenible, adoptado por los diversos niveles de gobierno y por diversas Organizaciones No Gubernamentales (ONG; López-Pardo, 2012; Araujo-Santana et al., 2013). No obstante, como ha ocurrido en otras regiones del mundo, el ecoturismo en México ha tenido resultados diversos. Algunos autores reportan impactos positivos del ecoturismo en la organización social local, pues genera una mayor inclusión social y constituye una actividad económica importante para el sustento familiar (Fuente y Ramos, 2013; Rosas y Correa, 2016). Otros reportan ventajas para la conservación, en términos de educación ambiental y la difusión de información (Guerrero, 2005; Díaz-Carrión, 2010; Pinkus-Rendón y Pinkus-Rendón, 2015). En contraposición, otras investigaciones muestran que el ecoturismo genera también exclusión social, mediante una distribución desigual de los beneficios, servicios y oportunidades (Greco, 2008), una mayor estratificación social y dudosos beneficios directos para la conservación y transformaciones ambientales, socioeconómicas y culturales importantes, tanto en las comunidades como en los territorios (Hernández et al., 2005; Brenner, 2006; Guzmán et al., 2013; Vargas del Río y Brenner, 2013). Otros autores reportan también impactos ambientales derivados del ecoturismo, como la proliferación de senderos, la erosión del suelo, la pérdida de vegetación, la contaminación del suelo y el agua e impactos a la vida silvestre (Buckley, 2005; Horton, 2009). Esta diversidad de resultados lo convierten en una estrategia polémica, pues se debate su capacidad de promover la conservación y el desarrollo. De acuerdo con Kieffer (2015), este debate se caracteriza por la polarización entre posturas poco críticas, centradas en resaltar sus beneficios o perjuicios. Sin embargo, ambas posturas suelen concebir al ecoturismo como una intervención externa, en la que las comunidades juegan el papel de receptores pasivos de proyectos.

Muchos de los proyectos ecoturísticos parten de un modelo de desarrollo exógeno, en el que las comunidades son el foco de las políticas públicas y cuyo desarrollo depende sólo de los actores externos (Long, 2007; Domínguez-Estrada, 2017). Diversos autores han mostrado cómo las intervenciones de conservación y desarrollo se diseñan a escalas globales y nacionales, a partir de generalizaciones que simplifican la realidad socioeconómica y ambiental en las que se insertan, para poder hacer operativa su implementación, sin embargo, esto oculta la heterogeneidad de las estructuras y necesidades locales (Li, 1996; Scott, 1998; Ascher, 2001). En este sentido, es necesario considerar que el ecoturismo es un proceso socialmente construido y negociado en la interacción que se establece entre diversos participantes, que influyen y son influidos por la dinámica socioeconómica y ecológica² de las iniciativas ecoturísticas y por los procesos sociopolíticos con los que se articulan a diferentes escalas, enmarcados en contextos específicos. Estos aspectos son de gran relevancia ya que podrían determinar el éxito o fracaso de las iniciativas ecoturísticas, tanto en términos socioeconómicos como ambientales (Agrawal y Gibson, 1999; Long, 2007; Wilshusen, 2009).

Los resultados de la implementación de proyectos ecoturisticos son producto de realidades emergentes construidas continuamente por los diferentes actores, sus intereses, perspectivas, relaciones y elementos culturales (Goffman, 1961; Schutz, 1962; Berger y Luckman, 1967). A partir de lo anterior, podemos decir que, para comprender la dinámica del ecoturismo es importante análizar el contexto local en el que se implementan los proyectos el ecoturismo para entender de qué manera la configuración de los contextos históricos, sociopolíticos y ambientales locales influyen en el desarrollo y resultado de los proyectos y comprender cómo el ecoturismo toma formas distintas en comunidades diferentes.

En México, el ecoturismo se ha implementado a lo largo de casi todo el país y el estado de Quintana Roo, con grandes atractivos turísticos, no es la excepción. La ciudad de Cancún, ubicada al norte de 
Quintana Roo, es uno de los principales destinos turísticos de México y recibe casi 17 millones de turistas al año. Esto representa 44\% del total de turistas que visitan el país, lo que genera ingresos superiores a $\$ 8,800$ millones de dólares (INEGI, 2016; SEDETUR, 2018). En Quintana Roo, el turismo es el principal motor de la economía regional, pero ha generado severos impactos ambientales y un desarrollo socioeconómico desigual. Ante esto, los gobiernos federal y estatal han promovido el ecoturismo como una alternativa para compensar las diferencias en el desarrollo social de las comunidades y promover la protección de los recursos naturales, particularmente en la región central del estado, la Zona Maya de Quintana Roo (ZMQR), cuyo desarrollo turístico es incipiente comparado con el resto del estado.

El objetivo de esta investigación es comprender cómo el fomento del ecoturismo, como política genérica de desarrollo comunitario produce modelos diferentes de ecoturismo, en función de los contextos históricos, sociopolíticos, económicos y ambientales en los que se implementa. En este estudio analizamos y comparamos dos iniciativas ecoturísticas en la ZMQR, una de carácter familiar (Community Tours Sian Ka'an), que lleva varias décadas trabajando en la Reserva de la Biosfera de Sian Ka'an (RBSK), y otra de tipo ejidal, Súijil Noh Ha, con pocos años de experiencia.

\section{Configuración de la región}

La configuración socioeconómica y ambiental actual del territorio de Quintana Roo está ligada a procesos histórico-sociales de larga data, como la Guerra de Castas, las migraciones dirigidas por el estado, el desarrollo de Cancún como polo turístico y, finalmente, el decreto de la RBSK.

La Guerra de Castas (1847-1901) fue un movimiento bélico maya contra el gobierno federal para liberarse de las condiciones de esclavitud prevalecientes desde el dominio español. Durante esta guerra las poblaciones mayas rebeldes migraron a la zona central del estado, hasta entonces despoblada (Hostettler y Restall, 2001)y que por esto no se descubre desde los navíos (sino. Al final de la guerra, el gobierno federal fomentó la migración y ocupación del territorio de Quintana Roo para aumentar la densidad poblacional y conformar un nuevo estado federal. Con estas migraciones también se establecieron diferentes industrias como la chiclera en 1920, la explotación forestal en 1930, la copra y la pesca comercial en la zona costera. Para la década de 1970 el gobierno federal incentivo la ganadería extensiva, las actividades agroindustriales y el turismo, que alcanzaron su auge con la creación de Cancún en 1970 como polo regional de desarrollo, controlado y planificado por el gobierno federal para generar empleos y desarrollo económico (Pérez y Carrascal, 2000; Daltabuit et al., 2000; 2007). Fue así como el turismo se posicionó como la principal actividad económica del estado, pues contribuye con casi $9 \%$ al producto interno bruto (PIB) nacional, y es una fuente de trabajo importante en la región (INEGI 2016; SEDETUR 2018). Sin embargo, este acelerado crecimiento económico no sólo aumentó la población del estado, sino que produjo también segregación social, pobreza, transformación de las actividades económicas, migración, expansión urbana, disminución de la cobertura vegetal, pérdida de manglares y ecosistemas costeros, y contaminación, entre otros (Pérez y Carrascal 2000; Córdoba et al., 2004; Arias-González y Lina-Manjarrez 2018).

De manera paralela al desarrollo turístico, en 1986 se decretó la RBSK, en la región central del estado. Esta reserva alberga a varios de los ecosistemas más representativos de la península de Yucatán y es considerada como una de las reservas más importantes del país (Arellano, 2004). Su decreto ocurrió gracias a la intervención de importantes ONG conservacionistas internacionales y regionales (The Nature Conservancy -TNC-, World Wildlife Fund -WWF- y Amigos de Sian Ka'an) que establecieron alianzas con actores locales para promover la creación del ANP. La reserva fue decretada por el gobierno federal y posteriormente respaldada por la UNESCO, al ser declarada Patrimonio Natural de la Humanidad. El decreto apoyó los intereses conservacionistas, pero también limitó las iniciativas gubernamentales para el desarrollo económico de la región (Brenner y Vargas del Río, 2010). Con el decreto de la RBSK, el turismo en Quintana Roo evolucionó de manera desigual: por un lado, el auge de la Zona Norte (de Cancún a Tulum), con un crecimiento acelerado y con Cancún como modelo de desarrollo turístico; por otro lado, la Zona Sur (Chetumal-Xcalak-Mahahual) centrada en el turismo de cruceros y finalmente, la Zona Maya, con un turismo incipiente, principalmente por carecer de zona costera, la cual es ocupada por la RBSK. Aunque esta configuración del territorio ha ayudado a preservar los recursos naturales, las actividades económicas y el uso tradicional de los recursos naturales, también ha influido en el desarrollo de políticas públicas a favor del turismo, con lo que se han acentuado las diferencias en el desarrollo socioeconómico entre distintas zonas del estado, así como la presión sobre la RBSK. Por ello, se ha fomentado el ecoturismo como estrategia de conservación y desarrollo en las comunidades de la ZMQR. 


\section{Métodos}

\subsection{Sitio de estudio}

La Zona Maya, llamada así por la concentración de comunidades mayas durante la Guerra de Castas, se ubica en la porción central del estado de Quintana Roo y colinda con la RBSK (Figura 1 y 2). La región tiene una población de más de 100 mil habitantes, en su mayoría indígenas (57\%) con un grado alto de marginación (SEDESOL, 2013). Las principales actividades económicas son la agricultura de subsistencia, la apicultura, la ganadería, las actividades forestales, así como el comercio y el turismo como actividades complementarias. Muchos jóvenes de la región trabajan en los hoteles y restaurantes del corredor turístico Cancún-Tulum (INEGI, 2010; Méndez-López, 2014; Santana et al., 2013). El desarrollo socioeconómico de la zona está rezagado con respecto al resto del estado y, frente al fomento del ecoturismo, algunas comunidades lo han adoptado como actividad económica complementaria desde hace 30 años (Daltabuit et al., 2000; Carballo-Sandoval, 2005). Algunos ejemplos de estas iniciativas ecoturísticas en la zona son Síijil Noh Ha (SNH) y Community Tours Sian Ka’an (CTSK).

Figura 1: Zona Maya de Quintana Roo.

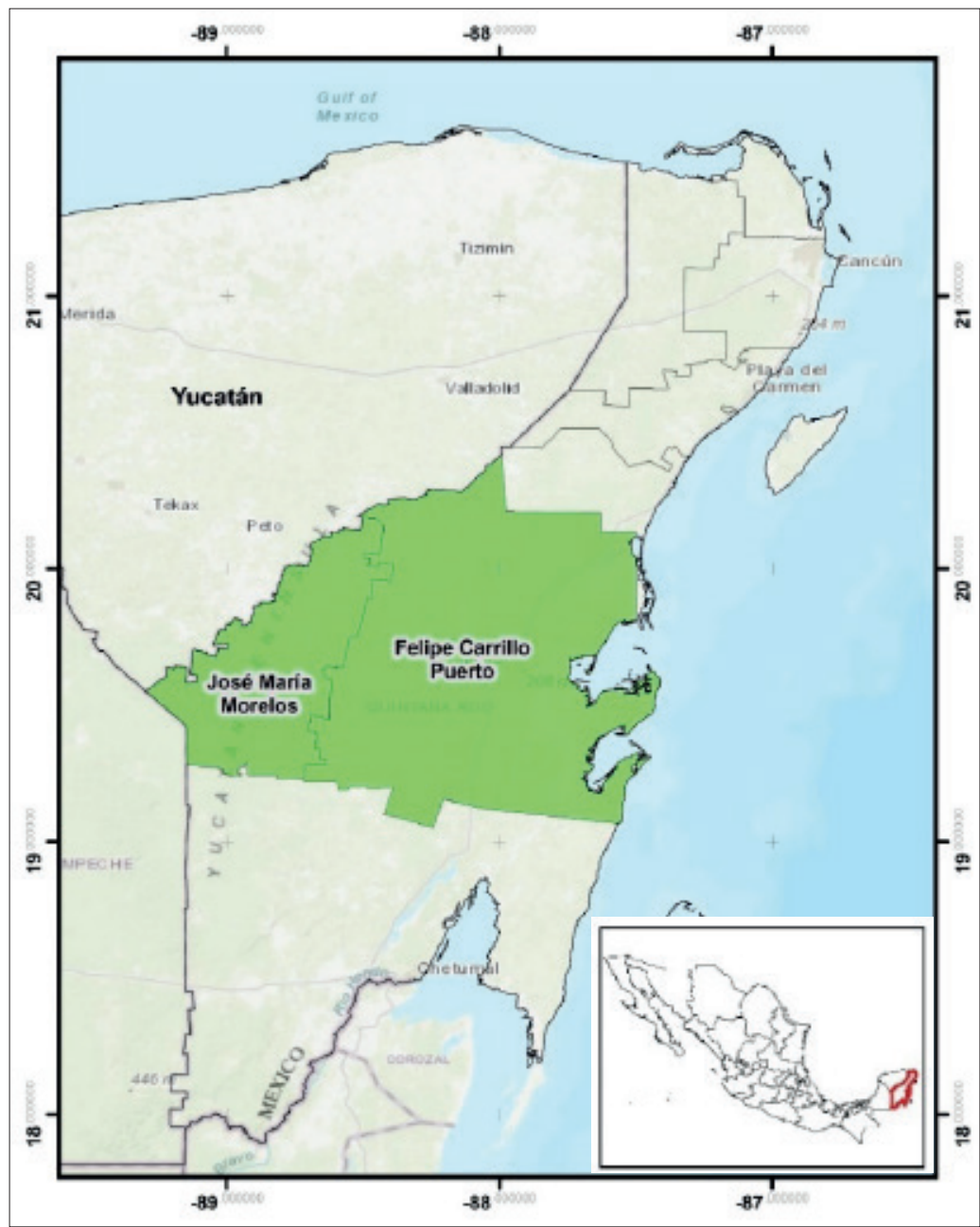

Elaboración propia. 


\section{Figura 2: Letrero de inicio de Zona Maya en la carretera federal 307 de Tulum a Felipe Carrillo Puerto, Quintana Roo.}

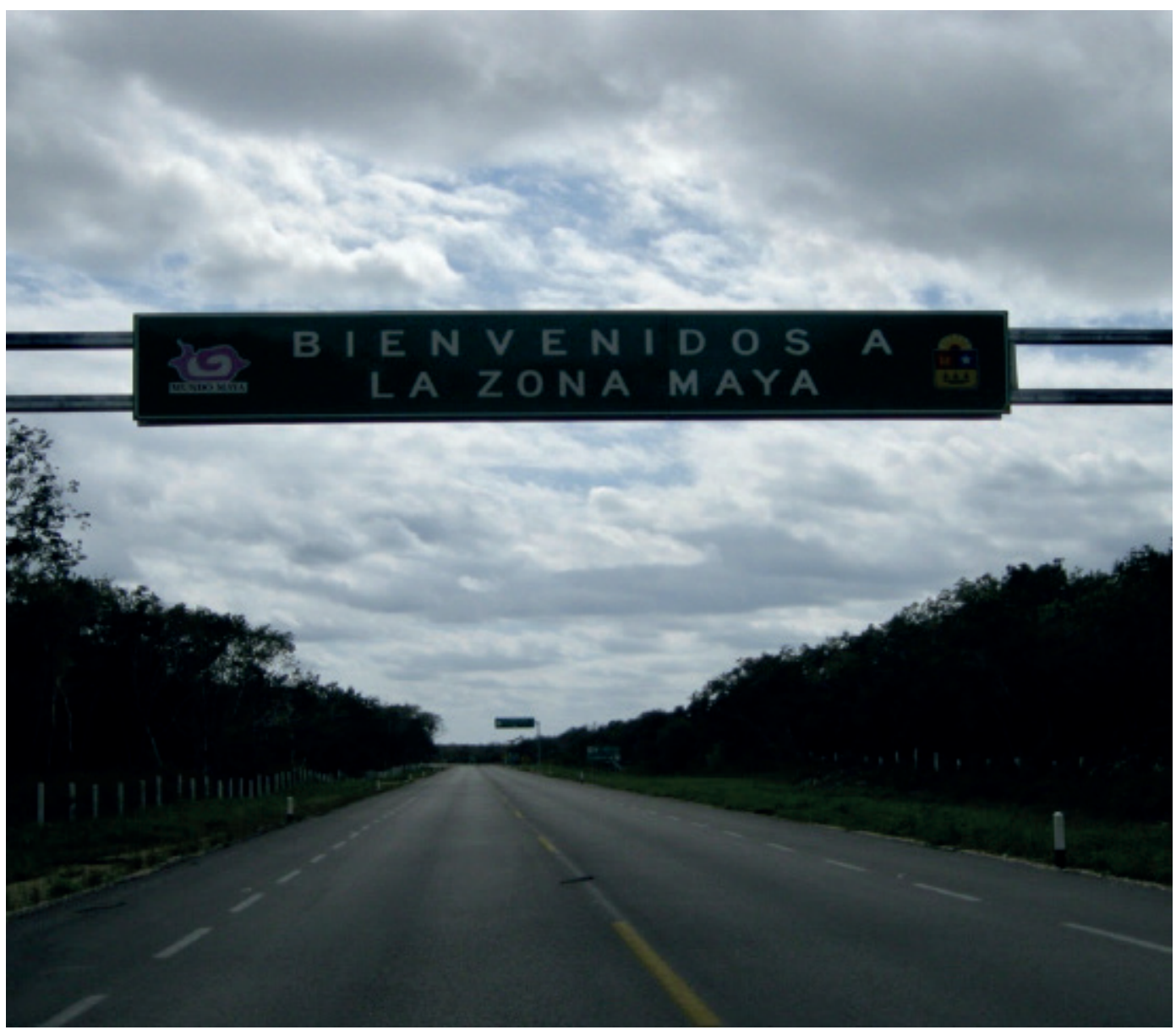

Elaboración propia.

\subsection{Métodos}

Para entender la importancia del contexto en el desarrollo de las iniciativas ecoturísticas comunitarias en la ZMQR, se realizó una visita de campo prospectiva en la que se eligió a las iniciativas SNH y CTSK, por el gran número de actores externos, vinculados con el ecoturismo, con los que relacionan (ONG, instituciones gubernamentales, operadoras turísticas, universidades, comunidades de la zona y otras iniciativas ecoturísticas comunitarias) y que operan a diferentes escalas.

Durante el trabajo de campo (marzo - agosto de 2019), se documentaron las dinámicas sociales y económicas en la operación de las iniciativas y su articulación con actores externos, así como las acciones en materia ambiental y el uso de los recursos naturales. Para esta documentación, se utilizaron diferentes herramientas cualitativas: (1) observación participante y no participante, (2) entrevistas etnográficas a actores clave vinculados con las iniciativas, así como 3) revisión bibliográfica sobre la historia del territorio y la evolución del turismo en la zona. La información recabada fue sistematizada y analizada a través del programa Atlas ti 7. Para ello se usaron las categorías empíricas y teóricas relacionadas con los conceptos que guiaron este proyecto. A partir de la sistematización y análisis de la información, se generaron mapas de actores con los que cada iniciativa está vinculada. Finalmente, se realizó una reflexión sobre las implicaciones teóricas de los segmentos codificados, en relación con la influencia del contexto en el origen de las iniciativas y en sus dinámicas socioeconómicas y ambientales. 


\section{Iniciativas ecoturísticas}

\subsection{Centro ecoturístico Síijil Noh Ha}

El centro ecoturístico Síijil Noh Ha (SNH, Figura 3) pertenece al ejido de Felipe Carrillo Puerto (FCP), un ejido compuesto por 251 ejidatarios, en su mayoría hombres (80\%), de entre 30 y 80 años, aunque la mayoría tienen alrededor de 70 años. Desde su conformación como ejido, en 1940, su principal actividad económica ha sido el aprovechamiento forestal; inicialmente, mediante la concesión de sus tierras, después en alianza con una organización regional de ejidos y, finalmente, de manera independiente con la ayuda de un asesor forestal. Este último hecho detonó su articulación con la ONG U'yool'ché (U'yool'ché, 2005). Luego de 60 años de explotación forestal, la disminución de los volúmenes maderables llevó al ejido a iniciar un plan de manejo integral de los recursos naturales para diversificar sus actividades económicas. Este plan incluyó el ordenamiento ecológico territorial del ejido, el establecimiento de dos reservas comunitarias, una de ellas reconocida formalmente por la Comisión Nacional de Áreas Naturales Protegidas (CONANP) como Área Destinada Voluntariamente a la Conservación (ADVC), un programa de manejo forestal sustentable, un plan de certificación de captura de carbono y la creación de un centro ecoturístico.

\section{Figura 3: Centro ecoturístico Síijil Noh Ha en Felipe Carrillo Puerto, Quintana Roo.}

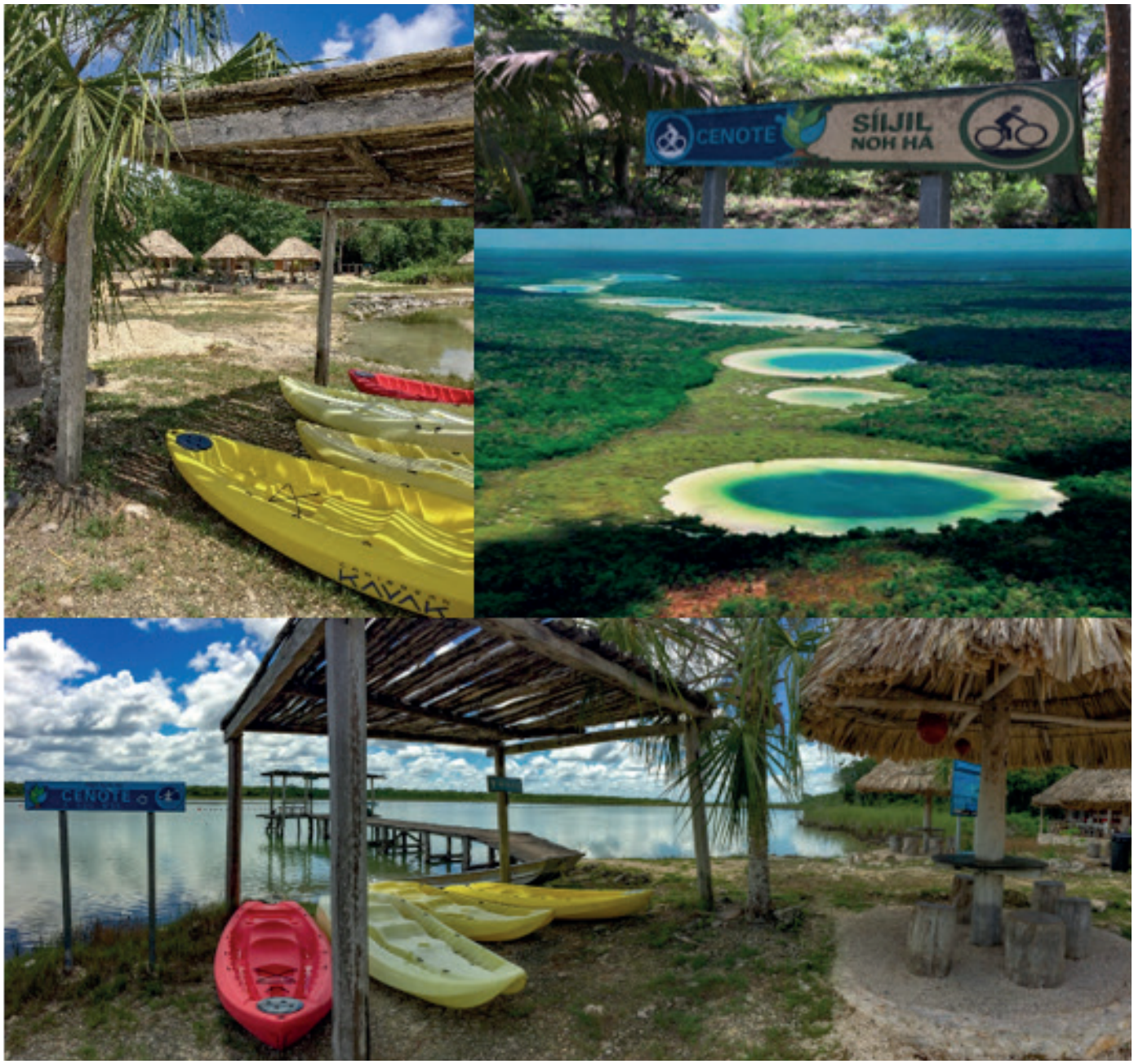


En 2009 se creó SNH, que se encuentra al interior del ADVC Much Kanan K’aax, a la orilla de la laguna Ocom. La iniciativa ecoturística ofrece servicios como renta de kayaks y bicicletas, nado en la laguna o en el cenote, además de seminarios y recorridos especializados a grupos. El sitio cuenta con una torre de observación, un eco-museo, senderos interpretativos, un cenote, palapas alrededor de la laguna, seis cabañas rústicas, área de literas, vestidores, área para acampar, comedor para 100 personas, cocina y sanitarios.

\subsubsection{Operación}

Uno de los principales retos para SNH es que se encuentra lejos de los principales destinos turísticos y a $10 \mathrm{~km}$ de la ciudad de Felipe Carrillo Puerto. Ante la baja afluencia turística y la falta de promoción

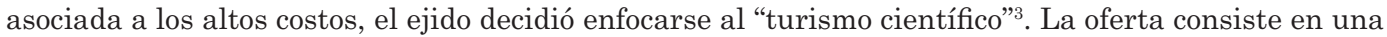
visita a SNH como parte de un recorrido integral a la ADVC, con seminarios sobre el manejo de los recursos naturales. Esta estrategia se fortaleció al registrarse como comunidad instructora de manejo forestal, ante la Comisión Nacional Forestal (CONAFOR).

$\mathrm{Al}$ pertenecer al ejido, la mayor parte de las decisiones relacionadas con $\mathrm{SNH}$ recaen en el comisariado ejidal, pero las decisiones más relevantes las toma la Asamblea Ejidal. La operación está a cargo de la tesorera del ejido, quien supervisa y dirige al equipo que labora en SNH, constituido únicamente por un grupo de cinco trabajadores que viven en FCP: vigilante, ayudante, encargado de mantenimiento, cocinera y encargada de la administración. Sólo tres de ellos son ejidatarios, pues las condiciones laborales (alejados de la ciudad, sin medios de transporte, incomunicados, con un salario de $\$ 2,040$ MXN quincenales, horas extras y días de descanso sin remuneración) y la elevada edad promedio de los ejidatarios, hacen que, para la mayoría de éstos, el trabajo en SNH resulte poco atractivo. Además, es un trabajo de tiempo completo que no les permite alternar con otras actividades económicas. Como consecuencia, la mayoría de los ejidatarios de FCP están desvinculados de lo que ocurre en el centro ecoturístico.

\subsubsection{Dinámica social}

La estructura de la organización en SNH da forma a las relaciones sociales al interior de la iniciativa, que responden a una estructura jerárquica, con relaciones asimétricas de poder, en donde los trabajadores juegan un rol de empleados frente al resto del ejido y carecen de participación directa en la toma de decisiones. Si bien los empleados conocen bien la dinámica, problemas y necesidades de SNH, esta información no es compartida con los ejidatarios, quienes, a su vez, están desvinculados de la iniciativa y desconocen la mayoría de los problemas del centro ecoturístico. Esta situación hace ineficiente la toma de decisiones de la Asamblea Ejidal en torno a SNH.

SNH ha logrado vincularse de manera sólida con instituciones gubernamentales, ONG y otras iniciativas ecoturísticas. El vínculo más importante es con la ONG U'yool'ché, que resultó clave en su articulación con otros actores. Las relaciones abarcan desde grandes instituciones como The Nature Conservancy (TNC), el Programa de las Naciones Unidas para el Desarrollo (PNUD), TUI Care Foundation, hasta instituciones más locales, como escuelas de educación primaria, media y superior de la región, a quienes les ofertan sus servicios ecoturísticos. Aunque actualmente el ejido se vincula directamente con estas instituciones, U'yool'ché aún colabora vinculando al ejido con otros actores. En términos institucionales, SNH también ha tenido una relación estrecha con la CONANP, ya que la iniciativa está situada en la primera ADVC de la península de Yucatán (Much Kanan K’aax). Sin embargo, su interacción con la CONANP está más bien articulada a través de la RBSK y con aspectos de manejo forestal que gestionan con la Secretaria de Medio Ambiente y Recursos Naturales (SEMARNAT) y CONAFOR (Figura 4).

Las relaciones que han establecido giran alrededor del financiamiento de proyectos, capacitación a los trabajadores de SNH y a miembros del ejido, y prestación de servicios turísticos que posteriormente se han articulado con otros proyectos, como el de captura de carbono. Sin embargo, el desarrollo de relaciones con otros actores externos se ha visto limitado por la estructura y organización de $\mathrm{SNH}$, ya que los trabajadores sólo se encargan de la operación del centro ecoturístico, pues el ejido está a cargo de su administración y dirección. El ejido carece de una vinculación cercana con las dinámicas de operación de $\mathrm{SNH}$, de manera que sólo ofrecen los servicios y no hay relaciones públicas. En la Figura 4 se observan las relaciones del ejido de FCP en torno al financiamiento, la capacitación con CONANP y SEMARNAT, así como la relación con organizaciones como TNC, TUI Care Fundation, CONAFOR e Instituciones educativas para la prestación de servicios y su articulación con Amigos de Sian Ka’an, la Comisión Nacional para el Conocimiento y Uso de la Biodiversidad (CONABIO), Comisión Nacional para el Desarrollo de los Pueblos Indígenas (CDI) y PNUD para la capacitación y financiamiento respectivamente. 
Figura 4: Mapa de actores de Síijil Noh Ha (SNH) y el ejido Felipe Carrillo Puerto (EFCP).

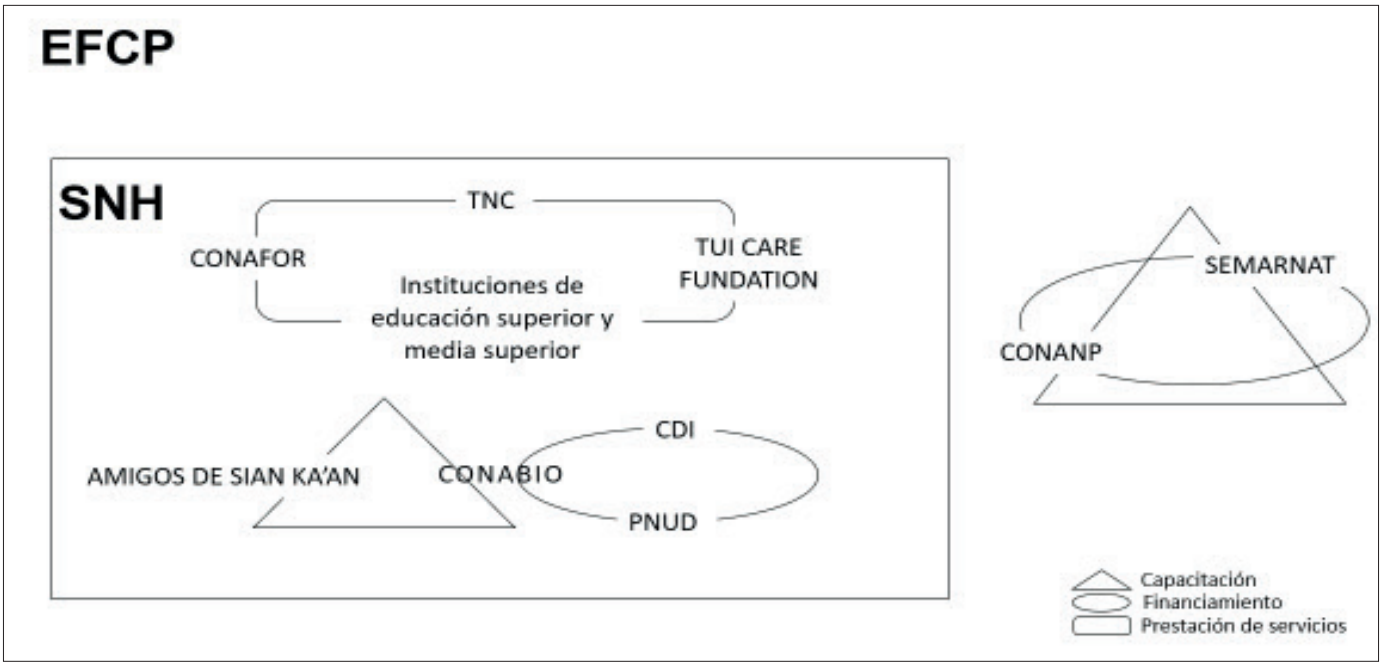

Elaboración propia.

\subsubsection{Dinámica económica}

El principal ingreso de SNH deriva de la visita de grupos interesados en el manejo de los recursos naturales del ejido, así como de turistas locales. Los ingresos generados se utilizan para pagar al personal que labora en el centro ecoturístico y las ganancias se reparten al final del año entre todos los ejidatarios (250 en total), con sumas que oscilan entre $\$ 4,000$ y $\$ 5,000$ pesos por ejidatario, lo que representa un ingreso para cada ejidatario de entre $\$ 300$ a $\$ 400$ pesos mensuales, cifra baja en comparación al ingreso promedio mensual en la zona (\$4,000 MXN/mes; Medina et al., 2017). Para algunos ejidatarios estos ingresos resultan insuficientes, comparados con lo que podrían ganar si concesionaran $\mathrm{SNH}$, como han hecho otras comunidades al concesionar el uso de sus recursos naturales a empresas privadas. Así, aunque SNH ha generado ganancias, éstas son insuficientes para que los ejidatarios la consideren como una actividad rentable. Ello da lugar a opiniones divididas en el ejido, sobre concesionar su uso o conservar su gestión.

\subsubsection{Dinámica ambiental}

Como centro ecoturístico, SNH forma parte de una estrategia integral de manejo comunitario de recursos naturales, en una zona que se caracteriza por ser el centro de diversos esfuerzos en materia de conservación. Por ello, la dinámica ambiental de la iniciativa se ha configurado por la influencia de los distintos actores e intereses que confluyen en la región (i.e. el desarrollo socioeconómico de las comunidades, el desarrollo del turismo y la conservación de los recursos naturales), en la que se imponen los intereses de los actores más importantes. En este sentido, debido a la vinculación de SHN con Amigos de Sian Ka'an y con la CONABIO, la iniciativa ha incorporado varias ecotecnias en el funcionamiento del centro ecoturístico, como paneles solares, biodigestores y un sistema de trampa de grasa en la cocina para evitar verter desechos a la laguna. Además, han adoptado varios de los lineamientos de conservación, como la prohibición de la caza, la pesca y la tala al interior del centro ecoturístico, al tiempo que desarrollan un monitoreo periódico de flora, fauna y de calidad del agua de la laguna. La adopción de estas acciones de conservación está directamente vinculada con la ADVC Much Kanan K'aax.

\subsection{Community Tours Sian Ka'an}

En la comunidad de Muyil se encuentra Community Tours Sian Ka'an (CTSK, Figura 5), una iniciativa que pertenece a la cooperativa familiar Muyil Conjunto de Aluxes (MCA). Esta cooperativa pertenece a una familia (los abuelos con al menos siete de sus hijos y toda su descendencia) que originalmente se estableció en Chanchen, una ranchería de Chunpom. Aunque sus actividades económicas eran la extracción de chicle, la milpa y la venta de durmientes para el ferrocarril, se han distinguido por autoorganizarse para buscar actividades económicas alternas (Tovar, 2017). En el año 2000, mientras 
la familia trabajaba en Muyil vendiendo muebles artesanales, observaron el arribo de turistas a la $\mathrm{RBSK}^{4}$, por lo que decidieron organizarse y obtener los permisos necesarios para ofrecer recorridos en los canales de flotación ${ }^{5}$. Así surgió la cooperativa, con seis miembros de la familia, a los que después se sumaron ocho más (primos, hermanos, cónyuges).

CTSK se ubica a $20 \mathrm{~km}$ de Tulum y su principal atractivo son los recorridos en los canales de la RBSK. También ofrecen recorridos de avistamiento de aves, flora y fauna en las zonas arqueológicas, la zona costera y recorridos a otras comunidades de la zona. Cuentan con siete lanchas, kayaks, dos camionetas, museo comunitario, mariposario, sendero interpretativo, sala de recepción para turistas, oficinas administrativas, bodegas, cuartos para voluntarios, estudiantes e investigadores, tienda de artesanías, comedor, cocina, baños y regaderas. Además, para ofrecer sus servicios ecoturísticos, cuentan con un sitio web y una oficina de ventas en Tulum.

Figura 5: Instalaciones de Community Tours Sian Ka'an.

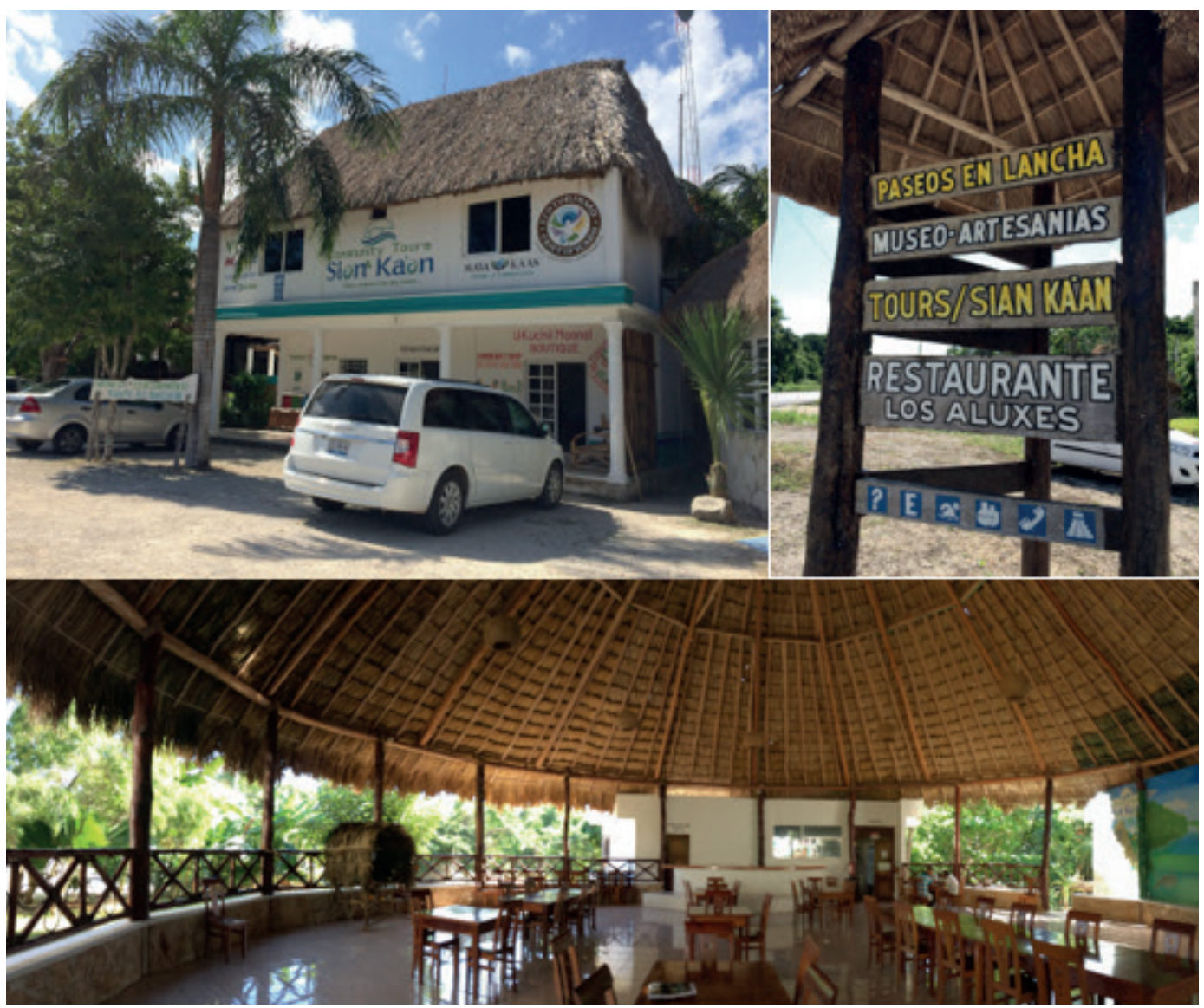

\subsubsection{Operación}

En un inicio, la cooperativa familiar MCA recibió capacitación de la SEMARNAT, de la Dirección de la RBSK y de la Secretaría de Turismo (SECTUR). Sin embargo, la capacitación más importante fue la del programa COMPACT (Community Management of Protected Areas Conservation Program) del PNUD, que resultó determinante en su integración al desarrollo ecoturístico de la zona. Este programa buscaba fortalecer a las cooperativas turísticas de la RBSK, formando guías bilingües y estableciendo vínculos con agencias para evitar la intermediación de las operadoras turísticas, de manera que las cooperativas recibieran directamente los beneficios económicos. 
La cooperativa MCA está conformada por 12 socios emparentados ente sí (58\% hombres y $42 \%$ mujeres) que, en su mayoría, trabajan en la empresa. Su organización consiste en una mesa directiva (presidente, secretario y tesorero) y una asamblea donde se toman las decisiones importantes (Figura 6). Mientras que CTSK está conformada por 41 empleados: 33 fijos y 8 eventuales (guías) y el personal está dividido en cinco áreas: operaciones, ventas y marketing, administración y finanzas, calidad y cocina. El gerente general supervisa todas las áreas y rinde cuentas al Consejo de Administración (i.e. la mesa directiva de la cooperativa) y a la Asamblea. De los trabajadores de CTSK, $59 \%$ son miembros de la familia y $29 \%$ tiene algún vínculo cercano con ellos. La mayoría de los trabajadores son oriundos de la ZMQR (88\%), principalmente de la comunidad de Chunpom (56\%), pero también hay gente de otros lugares (Chiapas y la Ciudad de México), aunque son minoría (12\%). CTSK atiende alrededor de 9 mil turistas anualmente, principalmente extranjeros. En este sentido, la mayoría del personal fijo (97\%) habla maya yucateco, su lengua materna, por lo que todas las interacciones al interior de la empresa se realizan en este idioma. Sin embargo, la mayoría de los trabajadores también hablan español (85\%) e inglés (46\%) y algunos francés e italiano, específicamente los guías.

\section{Figura 6: Estructura organizacional de la cooperativa familiar MCA y su iniciativa ecoturística CTSK.}

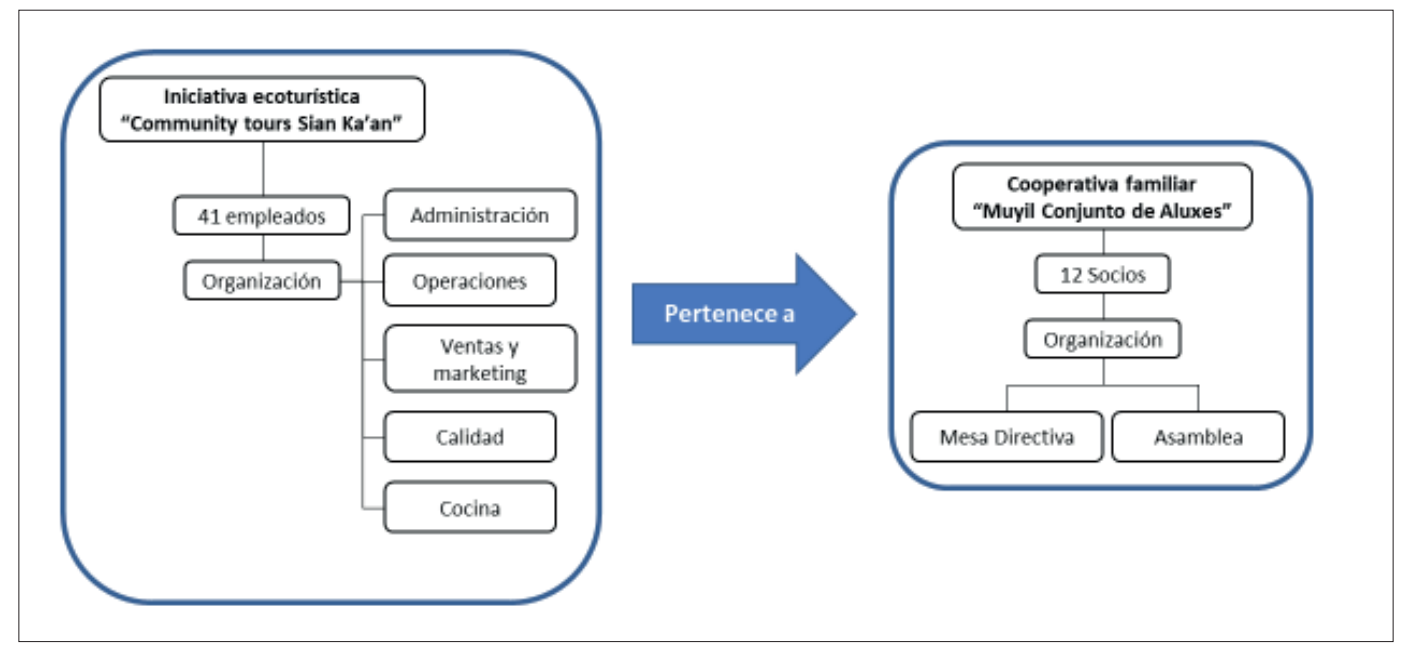

Elaboración propia.

\subsubsection{Dinámica social}

$\mathrm{Al}$ interior de CTSK, las decisiones importantes se toman por mayoría en la Asamblea de la cooperativa MCA, conformada por los 12 socios. A pesar de tener una estructura jerárquica, las relaciones familiares han permitido una organización cohesionada que, de acuerdo con algunos entrevistados, se basa en la colaboración, la empatía, la solidaridad, la reciprocidad, el bien común y, sobre todo, la confianza, lo que fortalece el tejido social al interior. Sin embargo, el parentesco no representa una ventaja o desventaja en el trato.

La iniciativa ecoturística se ha vinculado con instituciones gubernamentales como la CONANP y SEMARNAT por el hecho de trabajar dentro de la RBSK, con SECTUR debido a la importancia turística de la RBSK, con la CDI, con el Fondo Nacional de Apoyo a Empresas de Solidaridad (FONAES), con la Secretaria de Agricultura y Desarrollo Rural (SAGARPA), con el Fideicomiso del Riesgo Compartido (FIRCO) y con el PNUD, de quienes han recibido financiamiento. También se han vinculado con ONG como RARE, Amigos de Sian Ka'an, TNC y Sustentur, sobre todo en relaciones de cooperación y casi siempre vinculadas con la agenda de educación ambiental de estas ONG. También se han articulado con actores del sector turístico, como agencias, operadoras turísticas y hoteles. Finalmente, también trabajan con otras iniciativas comunitarias de la región en relaciones de cooperación y beneficio mutuo. Por un lado, CTSK enfrenta el problema de una alta demanda turística para visitar la RBSK, pero que 
está sujeta a la capacidad de carga establecida por la CONANP. Para no negar sus servicios turísticos, ofrecen recorridos a otras comunidades con las que colaboran. De esta manera, las otras iniciativas se benefician de la difusión de sus servicios turísticos y la recepción de turistas que les ofrece su alianza con CTSK.

La Figura 7 muestra que la relación de CTSK con todos estos actores es compleja y dinámica, pues se trata de actores de diferente naturaleza enfocados a la conservación, al turismo y al desarrollo, con intereses específicos y diferentes entre sí. Dependiendo de la situación, pueden establecer relaciones de cooperación, confrontación o negociación por el uso de los recursos naturales (SEMARNAT, CONANP) o por establecer precios justos (por ejemplo, con operadoras y agencias turísticas).

Figura 7: Mapa de actores de Community Tours Sian Ka'an.

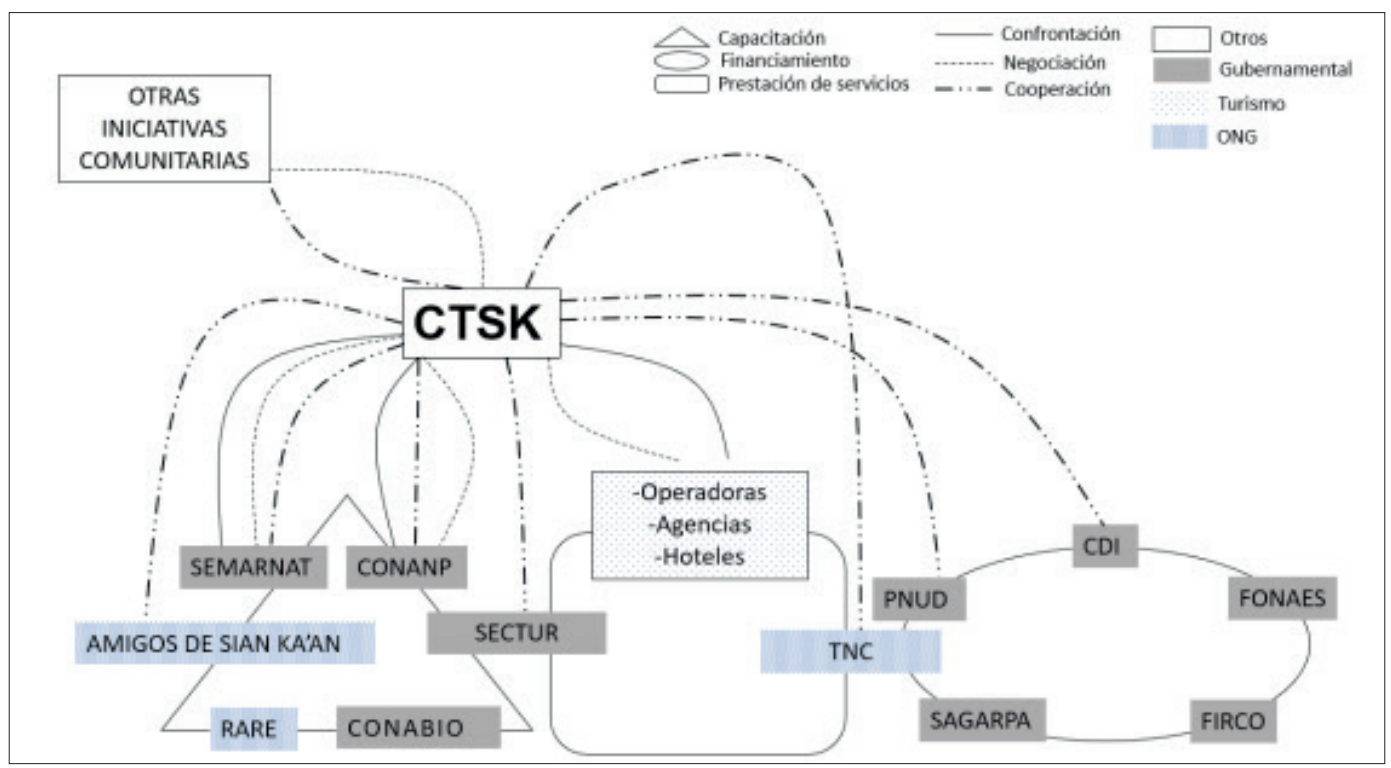

Elaboración propia

\subsubsection{Dinámica económica}

Los recorridos por los canales, junto con una buena estrategia de administración, les ha permitido convertirse en una iniciativa rentable. La estrategia de administración consiste en reinvertir constantemente las ganancias obtenidas para cubrir las necesidades emergentes de la empresa, así como la creación de un fondo contra desastres, la adquisición de material y equipo de trabajo, publicidad y mejoras a las condiciones laborales de los trabajadores. En CTSK, además de un salario fijo $(\$ 2,400 \mathrm{MXN}$ a $\$ 6,000$ MXN quincenales), los trabajadores reciben prestaciones como días de descanso y vacaciones pagadas, aguinaldo, préstamos personales, gastos médicos y están empezando a incorporar a los trabajadores a la seguridad social. Al igual que el resto de las iniciativas turísticas en la zona, la variación estacional de turistas a lo largo del año tiene un impacto en CTSK, por lo que han desarrollado estrategias grupales e individuales para sobrellevar las temporadas bajas. Por ejemplo, se otorgan días libres sin goce de sueldo al personal, quienes apoyan esta estrategia y la utilizan para dedicarse a otras actividades económicas complementarias (por ejemplo, el cultivo de pitahaya, el comercio o la apicultura).

\subsubsection{Dinámica ambiental}

$\mathrm{Al}$ realizar actividades ecoturísticas dentro de la RBSK, CTSK se ha vinculado con algunas acciones en materia de conservación. Por ejemplo, colaboran con las autoridades para la protección de la reserva, imparten talleres ambientales en escuelas locales y participan en programas ambientales, como el monitoreo semanal de aves con niños de la comunidad con el programa "Sal a pajarear Yucatán (Península)". También se han certificado como la primera empresa comunitaria Carbono Neutral en México, 
gracias al trabajo en conjunto con la ONG Sustentur. En colaboración con el proyecto Scolel'te, pionero en este tema en México, la iniciativa compensa la huella de carbono de sus actividades ecoturísticas. Además, su compromiso con la conservación está vinculado con la religión cruzoob, en la que se profesa el culto y respeto a la naturaleza, pues se concibe que todo tiene un dueño, por lo que para utilizar algún elemento de ésta es necesario realizar una ceremonia para pedirle al dios correspondiente (del bosque, del agua, de la caza, la luna, las abejas), que otorgue su permiso y protección. También se les agradecen los beneficios recibidos posteriormente, pues no hacerlo o abusar del uso de los recursos, puede representar un castigo. Esto se ve reflejado en los comentarios hechos por dos de los entrevistados:

“...somos católicos pero diferentes de los que hacen rezos en las iglesias, hacemos rezo en la milpa y las abejas”. “...yo hago ceremonia a la selva, a las abejas, todo lo que vemos tiene su espíritu, pertenece a un espíritu donde uno tiene que agradecer antes y después... la flor, la cera y la abeja tiene un dios y hay que pedir el polen se les regale a las abejas, porque si no, se guarda sin que las abejas la puedan recolectar".

\section{Discusión y Conclusiones}

La historia, así como las condiciones socioeconómicas, políticas y culturales de las comunidades rurales en las que se implementa el ecoturismo son de suma importancia en el desarrollo y alcances de los proyectos ecoturísticos. Este contexto influye en la forma de organización de las iniciativas que, a su vez, inciden en cómo i) surgen las iniciativas ecoturísticas; ii) se estructuran; iii) operan; iv) construyen sus redes de relaciones al interior y con actores externos; y v) desarrollan sus dinámicas ambientales. Nuestra investigación confirma que, más allá de compartir particularidades de un contexto regional, las iniciativas analizadas se constituyen en modelos diferentes de ecoturismo a partir de sus dinámicas y conformaciones particulares, con consecuencias diversas. Discutimos estos hallazgos a la luz de dos temas que consideramos importantes: a) el ecoturismo como estrategia genérica de conservación y desarrollo; b) la influencia de las formas de organización social en el desarrollo del ecoturismo.

El ecoturismo se propone como una de las actividades económicas más importantes para impulsar la conservación y el desarrollo local. Al igual que en el resto del país, su implementación en los dos casos de estudio analizados fue promovida por actores externos (agencias internacionales, instancias gubernamentales y $\mathrm{ONG}$ ), quienes jugaron un papel central, sobre todo aquellos vinculados con la conservación, el desarrollo social y el turismo mismo, quienes representan diversos intereses y objetivos, como se ha mostrado para otros casos en la región (Daltabuit et al., 2000; Barbosa-Polanco et al., 2010; Araujo-Santana et al., 2013). La adopción de esta estrategia por parte de las comunidades inició en la década de 1990. Entre los factores que la propiciaron están la disminución de la producción agrícola-forestal y las restricciones en el uso de los recursos naturales que implicó el establecimiento del ANP (Campos et al., 2008). Esto último es particularmente relevante en la ZMQR, por su importancia nacional e internacional para la implementación de programas de conservación, en buena medida porque alberga una de las zonas boscosas más grandes y diversas de México, así como a comunidades altamente marginadas (Faust, 2001; Porter-Bolland et al., 2007).

El ecoturismo, al igual que otras intervenciones de desarrollo y conservación, no es ajeno a los contextos y dinámicas locales en los que se implementa y en los que es adaptado y co-construido. De manera que los resultados de su implementación son producto de la construcción dialéctica de realidades emergentes entre los actores involucrados, junto con sus intereses, elementos culturales, perspectivas y relaciones, enmarcadas en contextos específicos (Goffman, 1961; Schutz, 1962; Berger y Luckman, 1967); así , aunque dos comunidades se encuentren en la misma región, la heterogeneidad socioeconómica, política y cultural origina soluciones alternativas a problemas similares (Long, 2007). Los resultados de nuestro estudio, precisamente, reflejan cómo dos iniciativas ecoturisticas de la misma zona han desarrollado modelos diferentes de ecoturismo, con distintas dinámicas socioeconómicas y ambientales. Estas diferencias están relacionadas con el lugar y la forma en los que operan, cómo está estructurada la iniciativa, el tipo de actores con los que interactúan y las relaciones que establecen con ellos, pero, principalmente, de los tipos de organización de los que provienen: SNH de una organización ejidal y CTSK de una cooperativa familiar.

Las diferencias en el desarrollo del ecoturismo basadas en el tipo de organización ya han sido reportadas por otros autores. Por ejemplo, Barbosa-Polanco y colaboradores (2010) analizaron el desarrollo de iniciativas ecoturísticas en la ZMQR, concluyendo que aquellas con una organización diferente a la ejidal tienen un mejor desarrollo. Por otro lado, estudios en la zona han reportado que 
las iniciativas ecoturísticas basadas en la organización de familias extensas obtienen mayores ingresos, sobre aquellas con otros tipos de organización (Araujo-Santana, 2012; García de Fuentes et al., 2015). Aunque nuestros resultados sólo describen las diferencias entre las dinámicas socioeconómicas y ambientales de ambas iniciativas, coinciden con lo reportado en la zona, pues permiten observar cómo en la iniciativa ejidal SNH aunque hay un reparto de beneficios económicos relativamente equitativo para un número importante de personas, tienen una organización ineficiente en la toma de decisiones, con poco involucramiento de los ejidatarios, mientras que en la iniciativa familiar CTSK hay una mayor cohesión social, mejor organización y mayores ingresos económicos. Estos resultados contrastan con la concepción idealizada de las iniciativas comunitarias, que generalmente son juzgadas de manera más positiva que una iniciativa privada o de esquema empresarial, por lo que son respaldadas e impulsadas institucionalmente por organizaciones gubernamentales, no gubernamentales y multilaterales, sobre todo en ANP con altos niveles de biodiversidad, pues se suele atribuir la conservación de estos territorios al conocimiento ancestral y al manejo de las comunidades (Borrini-Feyerabend y Oviedo, 2004; Vargas del Río, 2010). Sin embargo, se parte del supuesto de que este modelo representa el beneficio económico y la participación de toda la comunidad, así como la conservación de los recursos naturales, lo cual no necesariamente es cierto en todos los casos (Hernández et al., 2005; Brenner, 2006; Guzmán et al., 2013; Vargas del Río y Brenner, 2013).

Las iniciativas con un esquema cooperativo familiar, como CTSK, son consideradas como negocios familiares que benefician a un número reducido de personas, por lo que es necesario cuestionarse si estas empresas familiares pueden ser consideradas como iniciativas comunitarias o son un modelo de economía privada. Para responder esto, al menos para nuestro caso de estudio, es necesario analizar el contexto sociocultural e histórico del que proviene esta forma de organización, que responde más a una forma de organización tradicional que a un modelo económico. Los grupos domésticos o familiares son un tipo de organización común en culturas mesoamericanas, están formados por una o varias familias patrilineales de hasta cuatro generaciones, las cuales, a partir de su parentesco establecen relaciones de solidaridad, reciprocidad, cooperación, alianza y actúan como grupo productivo en las actividades económicas (Robichaux, 1995; Estrada-Lugo, 2005). Esta forma de organización social y productiva ha sido registrada en diferentes partes del país como Oaxaca (Sánchez-Morales et al., 2013), Chiapas (Favre, 1973; Brenton, 1984) y Quintana Roo, donde jugó un papel principal en la sociedad maya (Bello-Baltazar et al., 2002; Estrada-Lugo, 2005). En Quintana Roo, este tipo de organización tradicional conformaba los pequeños y dispersos asentamientos poblacionales en la zona, pero con la implementación de políticas públicas, se introdujeron otras formas de organización para el manejo de los recursos naturales, primero las cooperativas para la extracción del chicle y después la organización ejidal con la Reforma Agraria, que resultó en la creación de nuevos centros de población ejidal (Araujo-Monroy, 1997; Merino, 2004; Estrada-Lugo, 2005). Sin embargo, a pesar de las múltiples transformaciones sociopolíticas y económicas, los grupos familiares, como organización tradicional, han mostrado su resistencia al adaptarse a las nuevas condiciones (Estrada-Lugo, 2005; Rosales y Rubio, 2005). En el caso del ecoturismo, han logrado incorporarse al desarrollo de esta actividad, constituyéndose legalmente como cooperativas o asociaciones civiles para poder acceder a los proyectos y apoyos económicos impulsados en la zona, que no consideran este tipo de organización como válida en sus lineamientos (Rosales y Rubio, 2005; Araujo-Santana et al., 2013). Esto queda ejemplificado en nuestros resultados con la cooperativa familiar, dueña de CTSK que, a pesar de constituirse legalmente como cooperativa para cumplir con los lineamientos establecidos por las políticas de desarrollo y conservación, ha logrado mantener su organización familiar además de adaptarla a una visión y estructura empresarial para integrarse de manera exitosa al desarrollo del ecoturismo en la zona. Esto, sumado a su forma de operar y el contexto donde se desarrollan, les permite interactuar con una gran cantidad de actores de diferentes ámbitos, de conservación y turismo, con los que establecen diferentes tipos de relación, con características y dinámicas muy específicas, dependiendo del contexto en el que se den estas interacciones. Por su parte, en SNH la estructura y dinámica de operación ha limitado las interacciones con otros actores a la oferta de servicios turísticos.

Nuestros resultados muestran que la implementación del ecoturismo a través de dos formas diferentes de organización resultan en modelos distintos de ecoturismo, cada uno con sus ventajas y limitaciones. Sin embargo, la inserción del ecoturismo responde a múltiples y complejos procesos socioeconómicos políticos, culturales y ambientales, que operan a distintas escalas en el territorio y que inciden en la forma en que se desarrolla en los diferentes contextos. Estos procesos deben analizarse de manera que podamos comprender cómo se desarrolla el ecoturismo en regiones más amplias, involucrando más casos de estudio y preguntarnos cómo procesos socioeconómicos, políticos y ambientales, a diferentes escalas, influyen en el desarrollo del ecoturismo, cómo las interacciones sociales de las iniciativas con los 
diferentes actores involucrados en la promoción y operación del ecoturismo moldean su desarrollo, cómo es la interacción de estas iniciativas ecoturísticas con el resto de la comunidad y con otras iniciativas productivas.

A partir de las reflexiones anteriores, resulta necesario preguntarse en qué medida es pertinente el diseño de políticas públicas generales que no consideran las particularidades y complejidades de las dinámicas locales, cuando se busca conciliar la conservación y el bienestar local. Hasta ahora, el diseño de estas intervenciones responde a políticas homogéneas y estandarizadas, alineadas al discurso del desarrollo sostenible en la agenda internacional. El éxito o fracaso de las iniciativas y la diversidad de consecuencias positivas y negativas para el ambiente y la población local depende, en buena medida, de la diversidad de los modelos de ecoturismo que surgen en la interacción entre políticas generales y dinámicas locales -heterogéneas, aún en un contexto aparentemente homogéneo-, como ocurre en muy diversos contextos (Gibson, 1999; Long, 2007; Wilshusen, 2009).

\section{Bibliografía}

Agrawal A., y C. Gibson. 1999. "Enchantment and Disenchantment: The Role of Community in Natural Resource Conservation.” World Development 27 (4): 629-649.

Aguado I., Echebarria C.y Barrutia J. M. 2009. "El desarrollo sostenible a lo largo de la historia del pensamiento económico". Revista de Economía Mundial 21: 87-110.

Araujo-Monroy R. 1997. Los mayas migrantes de Quintana Roo. Tesis de licenciatura en Antropología Social del Departamento de Antropología de la Universidad Autónoma Metropolitana, Unidad Iztapalapa, México.

Araujo-Santana M. R. 2012. El rol del ecoturismo sobre los modos de vida de las comunidades rurales de quintana Roo, México. Tesis doctoral. Posgrado en Ciencias en Ecología y Desarrollo. Colegio de la Frontera Sur, México.

Araujo-Santana M. R., Parra-Vázquez M. R., Salvatierra-Izaba E. B., Arce-Ibarra A. M., Montagnini F. 2013. "Políticas turísticas, actores sociales y ecoturismo en la península de Yucatán". Economía Sociedad y Territorio 21(43): 641-671.

Arellano-Guillermo, A. 2004. "Site Management and Partnerships: The Sian Ka'an Biosphere Reserve Experience". Linking Universal and Local Values: Managing a Sustainable Future for World Heritage. World Heritage Papers 13: 136-141. Amsterdam. Recuperado de:

http://whc.unesco.org/documents/publi_wh_papers_13_en.pdf

Arias-González M. C. y Lina-Manjarrez P. 2018. "Paisaje, Turismo e Impacto Ambiental, Algunas Reflexiones Sobre Cancún.” En: García-Gómez, C., Bolio Rosado M. I., Navarro-Favela M. A. 2018. "Turismo y Sus Impactos Sociales, Económicos y Ambientales". Pp: 246-263. México: Universidad Intercultural Maya de Quintana Roo- Red de estudios multidisciplinarios de turismo-CONACYT.

Ascher, W. 2001. "Coping with Complexity and Organizational Interests in Natural Resource Management." Ecosystems 4 (8): 742-57.

Barbosa-Polanco S. C., Ofelia Molina D., Escalona Segura G., Bello Baltazar E. 2010. "Organización y ecoturismo en ejidos del sureste mexicano". Revista Estudios Agrarios 44 (16): 141-160.

Barkin D. y Pailles C. 1999. "NGO-Community Collaboration for Ecotourism: a strategy for sustainable regional development in Oaxaca". Planet, Global Journal of Practical Ecotourism.

Barkin D. 2005. "Building a future for Rural Mexico". Latin American Perspectives 33: 132-140.

Bello-Baltazar E., Erin I. J.; Mendoza P. M., Segundo A., Sánchez L. 2002. “Transdiciplina y sustentabilidad maya". Ciencia Ergo Sum 9 (3): 260-272.

Berger P., y Luckman T. 1967. The social construction of reality. Nueva York, EEUU. Dombleday. 240 pp.

Borrini-Feyerabend, G., Kothari A. y Oviedo G. 2004 Indigenous and Local Communities and Protected Areas: Towards Equity and Enhanced Conservation. Recuperado de: https://www.iucn.org/content/ indigenous-and-local-communities-and-protected-areas-towards-equity-and-enhanced-conservation

Brenner L. 2006. "Áreas Naturales Protegidas y Ecoturismo: El caso de la Reserva de la Biósfera Mariposa Monarca, México". Relaciones 105 (27): 237-265.

Brenner L. y Vargas del Río D. 2010. "Gobernabilidad y gobernanza ambiental en México. La experiencia de la Reserva de la Biosfera Sian Ka'an”. Polis 6 (2): 115-154.

Brenton A. 1984. Bachajón: Organización Territorial de una Comunidad Tzeltal. Instituto Nacional Indigenista. México 
Buckley R. 2005. Environmental Impacts of Ecotourism. Ecotourism Series 2. Wallingford, CABI Publishing. 389 pp.

Büscher B., Neves K., Igoe J. y Brockington D. 2012. "Towards a Ssynthesized Ccritique of neoliberal Bbiodiversity conservation”. Capitalism Nature Socialism 23 (2): 4-30.

Campos, B., Sierra, L., Balam, Y. 2008. La actividad turística internacional y su repercusión en la población de Quintana Roo. En: Fraga J., G. J. Villalobos, S. Doyon, A. García, Eds. 2008. Descentralización y manejo ambiental: Gobernanza costera en México. México: CINVESTAVIPN, 203-218 pp.

Carballo-Sandoval A. 2005. "Análisis de un modelo de desarrollo ecoturístico en Quintana Roo, México". Teoría y Praxis 1(1): 31-47.

Ceballos Lascurain H. 1993. Tourism, ecotourism and protected areas: national parks and protected areas. IV Congreso sobre Parques Nacionales y Zonas Protegidas, Caracas, Venezuela. 84-89 pp.

Córdoba O. J., García de Fuente A., Córdoba-Azcarate M. y Ayala-Arcipreste M. E. 2004. "Efectos locales de políticas globales: Celestún y su Reserva de la Biosfera (Yucatán, México)". Anales de Geografía 24: 55-78.

Croall J. 1995. Preserve or destroy: tourism and the environment. Londres: Calouste Gulbenkian Foundation. 180 pp.

Daltabuit M., Cisneros H. B., Vázquez L. y Santillán E. 2000. Ecoturismo y desarrollo sostenible: Impacto en comunidades rurales de la selva maya. Centro Regional de Investigaciones Multidisciplinarias, Universidad Nacional Autónoma de México. 357 pp.

Daltabuit M., Cisneros H. B. y Valenzuela Valdivieso E. 2007. "Globalización y sustentabilidad. El Turismo en el Sur de Quintana Roo". Universidad Nacional Autónoma de México, Centro Regional de Investigaciones multidisciplinarias. México. 165 pp.

Díaz-Carrión I. A. 2010. "Ecoturismo comunitario y género en la Reserva de la Biosfera Los Tuxtlas (México)". Pasos: Revista de Turismo y Patrimonio Cultural 8(1): 151-165.

Domínguez-Estrada J. F. 2017. Experiencias de turismo rural en Quintana Roo. Cuerpo Académico Turismo y Sustentabilidad. México. 260 pp.

Estrada-Lugo, E. 2005. "Grupo doméstico y usos del parentesco entre los mayas macehuales del centro de Quintana Roo. El caso del ejido Xhazil Sur y Anexos”. Tesis doctoral, Universidad Iberoamericana, México. 448 pp. Recuperado de: http://www.bib.uia.mx/tesis/pdf/014535/014535.pdf

Faust B. 2001. "Maya Environmental Successes and Failures in the Yucatan Peninsula." Environmental Science and Policy 4 (4-5): 153-169.

Favre H. 1973. Cambio y continuidad entre los Mayas de México. Contribución al estudio de la situación colonial en América Latina. Instituto Nacional Indigenista. México. 402 pp.

Fuente M. y Ramos M. F. 2013. "El ecoturismo comunitario en la Sierra Juárez-Oaxaca, México: entre el patrimonio y la mercancía". Otra Economía 7(12): 66-79.

García de Fuentes A., Jouault S. y Romero D. 2015. Atlas de turismo alternativo en la Península de Yucatán. Centro de Investigación de Estudios Avanzados del IPN-Unidad Mérida. Facultad de Ciencias Antropológicas de la Universidad Autónoma de Yucatán. 183 pp.

Goffman F. 1961. Encounters: two studies in the sociology of interaction. Harmondsworth: Penguin. $152 \mathrm{pp}$.

Greco O. 2008. Diccionario de Sociología. $2^{\mathrm{a}}$ ed. Florida: Valletta Ediciones. Buenos Aires, Argentina. $428 \mathrm{pp}$.

Guerrero E. 2005. Conservación Campesina en la Reserva de la Biosfera El Cielo, Tamaulipas, Tamaulipas, La Jornada Ecológica.

Guerrero-Rodríguez R. 2010. "Ecoturismo Mexicano: la promesa, la realidad y el futuro. Un análisis situacional mediante estudios de caso". El Periplo Sostenible 18: 37-67.

Guzmán M. G., Figueroa F. y Durand L. 2013. Ecología política y ecoturismo en México: reflexiones desde la Huasteca potosina y la Selva Lacandona. En: En busca del ecoturismo. Casos y experiencias del turismo sostenible en México, Costa Rica, Brasil y Australia, El Colegio de San Luis CONACYT-EÓN, México, 29-58 pp.

Hernández C. R., Bello-Baltazar E., Montoya-Gómez G. y Estrada-Lugo E. I. J. 2005. "Social Adaptation: ecotourism in the Lacandon Forest". Annals of Tourism Research 32(3): 610-627.

Horton L. R. 2009. "Buying Up Nature: Economic and Social Impacts of Costa Rica's Ecotourism Boom". Latin American Perspectives 36 (3): 93-107.

Hostettler U. y Restall M. 2001. "Mayan survivalism". Acta Mesoamericana 12: 323 pp.

Igoe, J., Neves K. y Dan Brockington. 2010. "A Spectacular Eco-Tour around the Historic Bloc: Theorising the Convergence of Biodiversity Conservation and Capitalist Expansion". Antipode 42 (3): 486-512. 
INEGI. 2010. Censo de población y vivienda 2010. En: <http://www.inegi.org.mx/ sistemas/mexicocifras/ default.aspx?src $=487 \& \mathrm{e}=23>$

. 2016. "Producto Interno Bruto Turístico." PIB y Cuentas Nacionales. En: http://www.inegi.org. $\mathrm{mx} / \mathrm{est} / \mathrm{contenidos/proyectos/cn/tur/default.aspx.}$

Jamal, T., Borges, M., y Stronza, A. 2006. "The institutionalization of ecotourism: Certification, cultural equity and praxis". Journal of Ecotourism 5(3): 145-175.

Kieffer M. 2015. La relación turismo - comunidades rurales: salir de la oposición de discursos. En: Nel-Lo A. M., Campos-Cámara B. L. y Sosa-Ferreira A. P. 2015. Temas pendientes y nuevas oportunidades en Turismo y Cooperación al Desarrollo. Red Internacional de investigadores en turismo, cooperación y desarrollo. EEUU. 479 pp.

Li, T. M. 1996. "Images of Community: Discourse and Strategy in Property Relations." Development and Change 27 (3): 501-27.

Long N. 2007. Sociología del desarrollo: una perspectiva centrada en el actor. Colegio de San Luis y el Centro de Investigaciones y Estudios Superiores en Antropología Social. México. 498 pp.

López-Pardo G. 2012. "Políticas gubernamentales para el desarrollo del turismo naturaleza en comunidades y pueblos indígenas en México". Patrimonio Cultural y Turismo. Cuadernos 19: 101-110.

Medina M. C., Cupiche V., Barbosa-Polanco S. 2017. Análisis socioeconómico de la Región Maya de Quintana Roo, su impacto en el desarrollo de los emprendimientos turísticos. En: Palafox-Muñoz A., Espinosa Sánchez R. y Dagostino Chávez M. R. (Eds.) 2017. Economía y conocimiento para el desarrollo regional sustentable. Universidad Autónoma de Nayarit, México. 276 pp.

Méndez-López M. E. 2014. Mecanismos de participación local en tres esquemas de conservación: Estudios de caso en el sureste mexicano. Tesis doctoral de la Universidad Autónoma de Barcelona. España. Recuperado de: https://ddd.uab.cat/pub/tesis/2014/hdl_10803_286182/meml1de1.pdf

Merino L. 2004. Conservación o deterioro. El impacto de las políticas públicas en las instituciones comunitarias y en los usos de los bosques de México. Secretaria de Medio Ambiente y Recursos Naturales, Instituto Nacional de Ecología y Consejo Civil Mexicano para la Silvicultura Sostenible A. C. México. 339 pp.

OMT. 2011. "Turismo y Reducción de La Pobreza." Disponible en: http://cf.cdn.unwto.org/sites/all/files/ docpdf/turismoyreducciondelapobreza.pdf.

Pena-Castro M. C. 2012. Estudio sobre turismo rural sostenible y su aplicación docente. Editorial Universidad Almería. 591 pp.

Pérez V. G. y Carrascal E. 2000. "El desarrollo turístico en Cancún, Quintana Roo y sus consecuencias sobre la cubierta vegetal”. Investigaciones Geográficas, Boletín del Instituto de Geografía, UNAM. 43: $145-166$ pp.

Pinkus-Rendón M. J. y Pinkus-Rendón M. A. 2015. "El ecoturismo: Quimera o realidad de desarrollo en la Reserva de la Biosfera Ría Celestún, México". Revista LiminaR: Estudios Sociales y Humanísticos 1: $69-80$.

Porter-Bolland Luciana, Edward A., L. Gholz E. 2007. "Land use dynamics and landscape history in La Montaña, Campeche, Mexico". Landscape and Urban Planning 82: 198-207.

Robichaux D. 1995. El modo de perpetuación de los grupos de parentesco: la residencia y herencia en Tlaxcala (México seguidas por un modelo para Mesoamérica. Tesis doctoral de la Universidad de Paris. 825 pp. Recuperado de: https://www.academia.edu/26959601/EL_MODO_DE_PERPETUACI\%C3\%93N_ DE_LOS_GRUPOS_DE_PARENTESCO_la_residencia_y_la_herencia_en_Tlaxcala_M\%C3\%A9xico_seguidas_por_un_modelo_para_Mesoam\%C3\%A9rica

Rosales G. M. y Rubio H. A. 2005. Organizaciones mayas para el desarrollo en el sur de Yucatán. Estudios de cultura Maya. Instituto de Investigaciones Filológicas, UNAM. Vol. XXVI 149-171 pp.

Rosas B. M. y Correa-Holguín D. A. 2016. "El ecoturismo de Sierra Norte, Oaxaca desde la comunalidad y la economía solidaria". Agricultura, Sociedad y Desarrollo 13: 565-584.

Sánchez-Morales J.C., Montoya-Gómez G., Bello-Baltazar E. 2013: “Autogestión y participación local en el centro ecoturístico "Cascadas El Corralito", Oxchuc, Chiapas". Teoría y Praxis 13: 107-132.

Santana R., Salvatierra-Izaba B., Parra-Vázquez M. R., Arce-Ibarra A. M. 2013. "Aporte económico del ecoturismo a las estrategias de vida de grupos domésticos de la Península de Yucatán, México". PASOS. Revista de Turismo y Patrimonio Cultural 11(1): 185-204.

Schutz A. 1962. The problem of social reality. La Haya: Mijhoff Publishers. 364 pp.

Scott, J. 1998. "Seeing like a State: How Certain Schemes to Improve the Human Condition Have Failed”. Yale University Press. EEUU. 461 pp. 
SEDETUR. 2018. “Reporte Anual de Turismo 2017.” Disponible en: http://qroo.gob.mx/sedetur/reporte-anual-de-turismo-2017.

SEDESOL. 2013. Catálogo Localidades. Unidad de Microrregiones En: http://www.microrregiones.gob. $\mathrm{mx} /$ catloc/LocdeMun.aspx?tipo=clave\&campo=loc\&ent=23\&mun=006

Tovar V. 2017. Áreas naturales protegidas, economía y turismo: Community tours Sian Ka'an, una historia para reflexionar el ecoturismo. Tesis de maestría. Posgrado en desarrollo rural. Universidad Autónoma Metropolitana. México.

U'yool'ché. 2005. Estudio de ordenamiento territorial del Ejido Felipe Carrillo Puerto. México. 95 pp.

Vargas del Río, D. 2010. Espacios comunitarios sujetos a conservación y turismo: retos para la gestión costera participativa. Tesis de doctorado, Universidad Politécnica de Cataluña, España.

Vargas del Río D. y Brenner L. 2013. Ecoturismo comunitario y conservación ambiental: la experiencia de la Ventanilla, Oaxaca, México. Estudios Sociales 21 (41): 32-63.

Wilshusen, P. 2009. "Social Process as Everyday Practice: The Micro Politics of Community-Based Conservation and Development in Southeastern Mexico.” Policy Sciences 42 (2): 137-62.

\section{Notas}

1 Este estudio usa la definición de ecoturismo de Ceballos (1993): “...modalidad turística ambientalmente responsable en áreas naturales, en la que se disfruta tanto de atractivos naturales como de manifestaciones culturales, y que promueve la conservación de los recursos naturales y el involucramiento activo de las poblaciones locales y su beneficio económico, mediante un bajo impacto socioambiental".

2 Este estudio, considera como dinámica social a la estructura organizacional al interior de la iniciativa, a las relaciones sociales tanto al interior de la iniciativa, como con actores externos vinculados al desarrollo del ecoturismo; como dinámica económica, lo referente a los ingresos, gastos, inversiones y repartición de ganancias y como dinámica ambiental, lo concerniente al uso, conservación y relación con los recursos naturales.

3 Es un segmento del turismo cultural y de experiencias enfocado a la divulgación científica, que consiste en visitar sitios con características naturales, para lograr un mayor entendimiento de la naturaleza desde una perspectiva científica (Pena-Castro, 2012).

4 La RBSK recibe más de 180 mil turistas al año. Aunque existen cinco accesos para visitarla, los más importantes son el de Muyil a 10 minutos de Tulum y el de Puerta Maya.

${ }_{5} \quad$ Serie de canales en la reserva de la Biósfera de Sian Ka'an preservados por las comunidades y que fueron construidos ancestralmente por los mayas. 